\title{
Hospital survey on patient safety culture in Ethiopian public hospitals: a cross-sectional study
}

\author{
Alemayehu B. Mekonnen ${ }^{1,2^{*}}$, Andrew J. McLachlan', Jo-anne E. Brien', Desalew Mekonnen ${ }^{3}$ and \\ Zenahebezu Abay ${ }^{4}$
}

\begin{abstract}
Background: Internationally, patient safety is increasingly seen as a priority area, and improving patient safety highly depends on achieving a culture that supports and encourages health care staffs to report their errors or near misses without fear of punishment. In Ethiopia, however, patient safety culture is a relatively new focus, and little is known regarding the current status of patient safety culture in public hospitals. The purpose of the current study was thus, aimed to assess the views and perceptions of health care professionals about patient safety culture in public hospitals in Ethiopia.
\end{abstract}

Methods: A cross-sectional study, utilizing the 'Hospital Survey on Patient Safety Culture (HSOPSC)' questionnaire was carried out in 2016 in the Amhara region. A self-administered questionnaire was distributed to the 480 health care staffs, including physicians, nurses, pharmacists, and other clinical and non-clinical staffs. Data were summarized as percentages, means, and standard deviations. ANOVA and chi-square tests were employed to examine statistical differences between health care worker's characteristics and patient safety predictors. We also computed internal consistency coefficients, correlation analysis, and exploratory factor analysis.

Results: A total of 410 questionnaires were returned (response rate, 85.4\%). The overall patient safety score (46\%) and most of the scores related to dimensions were lower than the benchmark scores. The positive response rate of two dimensions ('Teamwork within units' and 'Organizational learning-continuous improvement') received the highest score (each 72\%), and the lowest score was attributed to 'Staffing' (26\%). Approximately, two thirds of staffs reported at least one event in the past 1 year. Nurses reported better in the overall patient safety score compared with other health care professionals $(P=0.03)$. The internal consistency of the total survey was fairly satisfied (Cronbach's $a=0.77$ ).

Conclusions: There is a severe deficit of patient safety culture in Ethiopian public hospitals. Creating a positive patient safety culture by implementing actions that support all dimensions of safety culture is inevitable. Further research is needed to confirm the applicability of the translated version of the HSOPSC in the Ethiopian hospital settings.

Keywords: Patient safety, Patient safety culture, Hospital, Error reporting, Adverse event, Ethiopia

\footnotetext{
* Correspondence: aber5592@uni.sydney.edu.au

${ }^{1}$ Faculty of Pharmacy, University of Sydney, Sydney, Australia

${ }^{2}$ School of Pharmacy, University of Gondar, Gondar, Ethiopia

Full list of author information is available at the end of the article
}

(c) The Author(s). 2017 Open Access This article is distributed under the terms of the Creative Commons Attribution 4.0 International License (http://creativecommons.org/licenses/by/4.0/, which permits unrestricted use, distribution, and reproduction in any medium, provided you give appropriate credit to the original author(s) and the source, provide a link to the Creative Commons license, and indicate if changes were made. The Creative Commons Public Domain Dedication waiver (http://creativecommons.org/publicdomain/zero/1.0/) applies to the data made available in this article, unless otherwise stated. 


\section{Background}

Adverse events due to medical care remain a significant source of morbidity and mortality across the globe $[1,2]$ and have been identified as a matter of increasing priority for hospital managers and policy makers. However, much of the evidence base comes from developed countries as there is a paucity of published literature on patient safety in low- and middle-income countries [3]. Yet the magnitude of harm resulting from unsafe patient care is known to be large in these countries than in the developed nations [2, 4]. Until recently, patient safety in Africa has been absent from national policies but now has undergone renaissance through the WHO African Partnerships for Patient Safety (APPS) and increasingly seen as a basic right within the context of universal health coverage [5].

Despite a lack of research, patient safety in Ethiopia is believed to be a serious concern. A previous local study in the paediatrics ward has shown an incidence of 9.2 adverse drug events per 100 hospital admissions, of which one third could be preventable [6]. As health care managers strive to improve the quality of patient care, there is a growing recognition of the importance of establishing a culture of safety in Ethiopia [7]. Developing a patient safety culture was one of the recommendations made by the Institute of Medicine [8] to assist hospitals in improving patient safety. According to the Agency for Healthcare Research and Quality (AHRQ) [9], patient safety culture is described as an understanding of the values, beliefs, and norms about what is important in an organization and what attitudes and behaviours related to patient safety are supported, rewarded, and expected. It is, thus, important for health care organizations to assess their patient safety culture to obtain a clear understanding of the patient safety aspects requiring urgent attention, identify the strengths and weaknesses of their safety culture [10], and assist hospitals to identify their existing patient safety problems [11]. Studies on patient safety culture, mostly come from developed countries [10-13], have been published. In Ethiopia, however, patient safety culture is a relatively new focus, and little is known regarding the current status of patient safety culture in public hospitals. This study is part of a large project designed to implement patient safety programs [14], and it was included with the hypothesis that measuring patient safety culture is a priority step for a successful implementation of patient safety programs. Specifically, the current study was performed to assess the views and perceptions of health care professionals about patient safety culture in public hospitals in Ethiopia.

\section{Methods}

\section{Study design, setting, and population}

This is a cross-sectional study conducted over a 3month period (February-April 2016) in the Amhara region. Amhara region is one of the nine regions of
Ethiopia located in the northern parts of the country. This region has an estimated total population of approximately 18 million people, and the majority (87.4\%) of the population are rural inhabitants. This region has 17 public hospitals, 520 health centers, and 2941 health posts [15]. Health care professionals were recruited from ten hospitals of the region and involved physicians, nurses, pharmacists, and other clinical and non-clinical staffs (e.g. technicians). The sample size was estimated to be 480, and convenient sampling was used to select the participants. The methodology of this study was described elsewhere [14].

\section{Survey instrument}

This study adopted the 'Hospital Survey on Patient Safety Culture' (HSOPSC) developed by the Agency for Healthcare Research and Quality (AHRQ) [16], as a safety culture assessment instrument. The original HSOPSC has been validated in the USA hospital setting [17] and has also been widely employed to assess perceptions of hospital staff about patient safety issues, medical error, and event reporting in the non-US countries $[11,12]$. The instrument consists 42 items that measure 12 patient safety culture composites: 'Communication openness' (3 items), 'Feedback and communication about errors' (3 items), 'Frequency of events reported' (3 items), 'Handoffs and transitions' (4 items), 'Management support for patient safety' (3 items), 'Non-punitive response to error' (3 items), 'Organizational learning-continuous improvement' (3 items), 'Overall perceptions of patient safety' (4 items), 'Staffing' (4 items), 'Supervisor/manager expectations and actions promoting safety' ( 4 items), and 'Teamwork across and within units' ( 4 items each). In our study, however, there was one item that was not applicable to fit the Ethiopian context. A statement about 'Staffing' which reflects the use of agency/temporary staff for patient care was not included in this questionnaire. It is unlikely to employ an agent or a temporary staff in public hospitals in Ethiopia.

The response to each item in the questionnaire was assessed using a 5-point Likert scale of agreement (from 1: 'Strongly disagree' to 5: 'Strongly agree') or frequency (from 1: 'Never' to 5: 'Always'). There were also two single-item outcome variables: the overall patient safety grade (measured on a scale of 'Excellent', 'Very good,' 'Acceptable, 'Poor', and 'Failing') and the number of events reported in the past 12 months.

Background variables of participants included questions related to job category, type of hospital (teaching/referral, district), work experience (overall and in the current working area), work setting, and working hours per week.

The questionnaire is kept in English, as English is the main language of communication in Ethiopian hospitals. This paper-based questionnaire together with the participant information statement was distributed to the selected 
hospitals and participants by a person recruited for this purpose and required about $10-15 \mathrm{~min}$ to complete. Health care staffs who worked in their respective hospital for at least 6 months prior to the administration of the questionnaire were included in the study.

\section{Data analysis}

We entered the collected data and analysed using SPSS Version 21. Descriptive statistics were used to summarize the demographic data and scores of patient safety culture dimensions/items and safety outcomes (patient safety grade, the number of events reported). The HSOPSC included both positively and negatively worded items. For easier interpretation of the results, the AHRQ [16] and other studies [10-13] recommend the use of average positive' for calculating each item scores. Percent positive is the percentage of positive responses (e.g. Agree, Strongly agree) to positively worded items (e.g. 'People support one another in this unit') or negative responses (e.g. Disagree, Strongly disagree) to negatively worded items (e.g. 'We have safety problems in this unit'). That is, for positively worded items, responses 4 and 5 corresponded to positive answers whereas this meant responses 2 and 1, respectively, for the negatively worded items. Composite-level scores were computed by summation of the items within the composite scales and dividing by the number of items with non-missing values. We defined areas of strengths as items for which $75 \%$ of the respondents answered positively, whereas areas requiring improvement as those scored below 50\% [9].

Cross tables were constructed, and chi-square test was used to examine the statistical difference between health care workers' characteristics-such as the type of hospital they are working, profession, and work experience-and patient safety grade and the number of events reported. We also used ANOVA to examine differences in patient safety culture composites across these characteristics.

We used Cronbach's alpha $(\alpha)$ to evaluate the reliability of the questionnaire. Reliability greater than or equal to 0.7 (indicating that the items measure the same concept) has been taken as an acceptable level of internal consistency [18]. The construct validity was examined using Pearson's correlation coefficient between two scale scores. $P$ value < 0.05 was considered as statistically significant. Bartlett's test of sphericity was used to determine the sufficiency of interitem correlations. The sampling adequacy was determined using the Kaiser-Meyer-Olkin (KMO) measure. Exploratory factor analysis was performed using principal component analysis with varimax rotation.

\section{Results}

\section{Characteristics of respondents}

A total of 480 questionnaires were distributed; of which, 410 were returned, giving a response rate of $85.4 \%$. Many of the respondents were nurses (39.3\%) and were employed in the medical unit (22.9\%). The majority of respondents reported work experience of less than 1 year both in their current hospital and unit. Most had work duties of 40-59 h per week (54.8\%). More than half of the respondents were from teaching/referral hospitals, and 95\% reported their work involves direct patient care (Table 1).

\section{Patient safety culture dimensions}

In this study, the percentage of positive responses for the 12 patient safety culture dimensions ranged from 26 to $72 \%$, and the mean positive responses for all dimensions were $46 \%$. The lowest positive response rate of dimension was 'Staffing' (26\%), while the highest positive response rate of dimensions was 'Organizational learning-continuous improvement' and 'Teamwork within units' (each $72 \%$ ). In the remainder of dimensions, except for 'Teamwork across units' (57\%), all composite scores were less than $50 \%$.

\section{Comparison of safety culture dimensions}

When comparing the mean composite scores against the international benchmark, our study has found only one comparable average positive score; that is, 'Organizational learning-continuous improvement' with the score obtained from 680 hospitals in the USA [19]. There was also one comparable mean score related to 'Teamwork across units' with the data from 68 Lebanese hospitals [20] but better score in the 'Non-punitive response to error'. The rest composites had less average positive scores than the USA and the Lebanese data (Fig. 1).

\section{Patient safety culture items}

In the present study, the positive response rate for each of the items ranged from 22 to $85 \%$. The highest positive response rate of the items was 'We are actively doing things to improve patient safety' ( $85 \%)$, while the lowest positive response rate of the item was 'Staff in this unit work longer hours than is best for patient care' (37\%). Altogether, there were 24 items (of 41 safety culture items) with less than $50 \%$ of the average positive score (Table 2).

\section{Safety culture outcomes}

In this study, the percentage of health care staff who rated the level of patient safety grade as 'Very good' or 'Excellent' was $37.6 \%$ which was lower than the USA (76\%) and the Lebanese score (73.4\%) (Fig. 2). On the contrary, two thirds of the Ethiopian staffs reported at least one event over the past 12 months whereas only $45 \%$ in the USA and $41 \%$ in the Lebanon did (Fig. 3). There were significant differences in the responses to patient safety grade and the number of events reported between this study and the benchmark countries (all $P<0.0001$ ). 
Table 1 Socio-demographic and professional characteristics of respondents

\begin{tabular}{|c|c|}
\hline Characteristics & $N(\%)$ \\
\hline \multicolumn{2}{|l|}{ Working unit } \\
\hline Medical unit & $94(22.9)$ \\
\hline Surgery & $31(7.6)$ \\
\hline Gyn/Obs & $53(12.9)$ \\
\hline Paediatrics & $40(9.8)$ \\
\hline Pharmacy & $71(17.3)$ \\
\hline Laboratory & $28(6.8)$ \\
\hline Others ${ }^{a}$ & $93(22.7)$ \\
\hline \multicolumn{2}{|l|}{ Staff position } \\
\hline Nurses & $161(39.3)$ \\
\hline Physicians & $82(20.0)$ \\
\hline Pharmacists & $71(17.3)$ \\
\hline Technicians & $35(8.5)$ \\
\hline Others $^{\mathrm{b}}$ & $61(14.9)$ \\
\hline \multicolumn{2}{|l|}{ Years in hospital } \\
\hline$<1$ year & $235(57.3)$ \\
\hline $1-5$ years & $139(33.9)$ \\
\hline $6-10$ years & $25(6.1)$ \\
\hline $11-15$ years & $7(1.7)$ \\
\hline $16-20$ years & $1(0.3)$ \\
\hline$\geq 20$ years & $3(0.7)$ \\
\hline \multicolumn{2}{|c|}{ Years in current department } \\
\hline$<1$ year & $236(57.6)$ \\
\hline $1-5$ years & $146(35.6)$ \\
\hline $6-10$ years & $21(5.1)$ \\
\hline $11-15$ years & $4(1.0)$ \\
\hline $16-20$ years & $2(0.5)$ \\
\hline$\geq 20$ years & $1(0.2)$ \\
\hline \multicolumn{2}{|l|}{ Work experience } \\
\hline$<1$ & $168(41.0)$ \\
\hline $1-5$ years & $190(46.3)$ \\
\hline $6-10$ years & $37(9.0)$ \\
\hline $11-15$ years & $5(1.2)$ \\
\hline $16-20$ years & $4(1.0)$ \\
\hline$\geq 20$ years & $6(1.5)$ \\
\hline \multicolumn{2}{|c|}{ Working hours per week ${ }^{c}$} \\
\hline$<20 \mathrm{~h}$ & $10(2.5)$ \\
\hline 20-39 h & $66(16.2)$ \\
\hline $40-59 h$ & $223(54.8)$ \\
\hline $60-79 \mathrm{~h}$ & $63(15.5)$ \\
\hline $80-99$ h & $23(5.6)$ \\
\hline$\geq 100 \mathrm{~h}$ & $22(5.4)$ \\
\hline
\end{tabular}

Table 1 Socio-demographic and professional characteristics of respondents (Continued)

Type of hospital

District

$184(44.9)$

Teaching or referral

$226(55.1)$

Contact with patients

Yes

$388(95.0)$

No

$22(5.0)$

ancludes orthopaedics, general ward, outpatient department, drug

information center, dental clinic, and eye clinic

bIncludes druggist, anaesthetist, health officer, reproductive health specialist,

emergency surgeon, dental surgeon, optometrist, anaesthetic nurse, and clinical ophthalmic assistance

'Three missing values

Demographic characteristics that influence safety culture dimensions, patient safety grade, and number of events reported

Comparison of scores for the dimensions of patient safety culture revealed better results for district hospitals compared with those of teaching/referral hospitals in terms of 'Communication openness' $(P=0.01)$, 'Organizational learning-continuous improvement', and 'Teamwork across units' $(P=0.02)$. Overall, the nurse's perception of patient safety culture was higher $(P=0.03)$, and specifically, higher scores for the dimensions 'Organizational learning-continuous improvement' $(P=0.004)$ and 'Management support for patient safety' $(P=0.000)$ were reported from nurses than other health care staffs. Higher scores were observed in those staffs with less work experience for the dimension 'Organizational learning-continuous improvement' (Additional file 1). Additionally, cross table results showed that nurse staffs were more likely to report an 'excellent/very good' patient safety grade $(P=0.001)$, while health care staffs from other category were more likely report at least one event in the past 12 months than the other counterparts $(P=0.006)$ (Table 3$)$.

\section{Reliability and validity}

Reliability analysis of the 41 items showed satisfactory internal consistency, i.e. Cronbach's $\alpha=0.77$, and ranged from 0.16 to 0.75 for the dimensions (Table 2). The dimension 'Staffing' had the lowest Cronbach's $\alpha$ value whereas 'Frequency of events reported' had the highest coefficient. Despite having no effect on the overall survey reliability, exclusion of the item 'Hospital management seems interested in patient safety only after an adverse event happens' would result in the 'Management support for patient safety' dimension reliability increasing from 0.48 to 0.70 .

Table 4 shows the inter-correlations of the 12 dimensions and correlations between the total patient safety score and each dimension. 'Organizational learningcontinuous improvement' is the dimension which was 


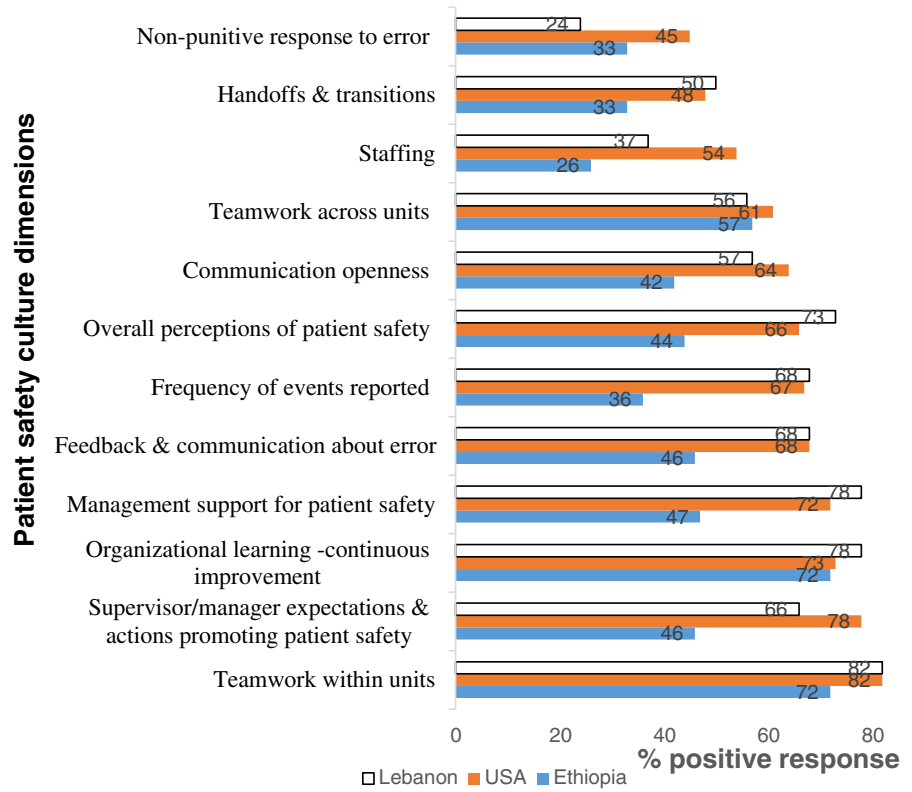

Fig. 1 Comparison of mean patient safety culture composite scores of Ethiopian public hospitals and benchmark scores [19, 20]. The composite-level percentage of positive responses was calculated using the following formula: [number of positive responses to the items in the composite/total number of responses to the items (positive, neutral, and negative) in the composite (excluding missing responses)] $\times 100$

most correlated with 'Team work within units' $(r=0.58)$ but also the least correlated with 'Handoffs and transitions' $(r=0.01)$. The highest correlation was observed between 'Feedback and communication about errors' and the overall scale $(r=0.68)$. Ten of the 12 dimensions were significantly correlated with the total scale.

Barlett's test of sphericity for the questionnaire demonstrated sufficient inter-item correlations $\left(\chi^{2}=3805\right.$; $\mathrm{df}=820, P=0.000$ ), and the KMO measure of sampling adequacy was satisfactory 0.858 . Exploratory factor analysis extracted 11 factors which explained $59.3 \%$ of the variance. Four items (A7, A8, A10, A13) from the original questionnaire were dropped based on factor loadings for each item (all loadings $>0.40$ ). The distribution of the items among dimensions was found to be different from that in the AHRQ model; except the dimensions 'Supervisor/manager expectations and actions promoting safety' (items B1 to B4) and 'Frequency of events reported' (items D1 to D3), the remaining items were clustered into several two or three dimensions not fitting to the factor structure of HSPOSC (Additional file 2).

\section{Discussion}

Assessing and promoting a culture of safety is recognized as a prerequisite step towards improving patient safety [21]. Culture assessment tools, such as the HSOPSC, provide an avenue for understanding the existing patient safety issues and increasingly utilized to gauge the changes in culture over time $[19,22]$. The present study investigated the current status of patient safety culture in
Ethiopian public hospitals using the HSOPSC instrument. The results of this study revealed that the overall positive response rate for all dimensions of the HSOPSC survey was not satisfactorily enough, akin to the findings from another local study [23]. Wami et al. [23] assessed the patient safety culture in Jimma Zone (Oromia region) and have found that the overall mean score for the positive perception of patient safety culture dimension was $46.7 \%$. However, our study scored lower results when compared with the findings from other low- and middle-income countries (e.g. China (65\%) [18], Lebanon (61.5\%) [20], Saudi Arabia (61\%) [24], Palestine (54\%) [25], Taiwan (64\%) [26]), and developed countries (e.g. the USA (65\%) [19] and the Netherlands (52.2\%) [13]). Of all the patient safety culture composites, there was none that fits the criteria for areas of strength. This also showed a severe deficit of patient safety culture in the studied hospitals. This is not a surprising fact given the tremendous work and emphasize on universal health care coverage, and interest in quality is only a recent move. Despite significant improvements in health care services, issues related to quality and safety have been inconsistently integrated into the Ethiopian health care system but, recently, the government ratified strategies for improving quality nationwide in the next 5 years (2016-2020) [27].

This study has identified many areas that need improvement. For example, the dimensions that received the highest positive response but yet needs some improvement were 'Teamwork within units' and 'Organizational learning-continuous improvement'. These dimensions were 
Table 2 Percent average positive response for an item-level and composite

\begin{tabular}{|c|c|c|}
\hline Composites and items & $\%$ positive $^{a}$ & Mean (SD) \\
\hline Teamwork within units (Cronbach's $a=0.71$ ) & 72 & $3.66(0.75)$ \\
\hline A1. People support one another in this unit & 83 & $3.89(0.93)$ \\
\hline A3. When a lot of work needs to be done quickly, we work together as a team to get the work done & 74 & $3.74(0.99)$ \\
\hline A4. In this unit, people treat each other with respect & 75 & $3.75(1.01)$ \\
\hline A10.When one area in this unit gets really busy, others help out & 56 & $3.27(1.20)$ \\
\hline Supervisor/manager expectations and actions promoting patient safety (Cronbach's $a=0.48$ ) & 46 & $3.11(0.48)$ \\
\hline $\begin{array}{l}\text { B1. My supervisor/manager says a good word when he/she sees a job done according to established patient safety } \\
\text { procedures }\end{array}$ & 62 & $3.44(1.13)$ \\
\hline B2. My supervisor/manager seriously considers staff suggestions for improving patient safety & 61 & $3.39(1.11)$ \\
\hline B3. Whenever pressure builds up, my supervisor/manager wants us to work faster, even if it means taking shortcuts $(R)^{b}$ & 28 & $2.77(1.05)$ \\
\hline B4. My supervisor/manager overlooks patient safety problems that happen over and over $(R)$ & 33 & $2.82(1.15)$ \\
\hline Organizational learning-continuous improvement (Cronbach's $a=0.54$ ) & 72 & $3.74(0.74)$ \\
\hline A6. We are actively doing things to improve patient safety & 85 & $4.02(0.97)$ \\
\hline A8. Mistakes have led to positive changes here & 63 & $3.49(1.04)$ \\
\hline A12. After we make changes to improve patient safety, we evaluate their effectiveness & 69 & $3.69(1.04)$ \\
\hline Management support for patient safety (Cronbach's $a=0.48)$ & 47 & $3.08(0.88)$ \\
\hline F1. Hospital management provides a work climate that promotes patient safety & 51 & $3.09(1.30)$ \\
\hline F8. The actions of hospital management show that patient safety is a top priority & 52 & $3.28(1.27)$ \\
\hline F9. Hospital management seems interested in patient safety only after an adverse event happens (R) & 37 & $2.89(1.12)$ \\
\hline Feedback and communication about error (Cronbach's $a=0.71)$ & 46 & $3.31(0.91)$ \\
\hline C1. We are given feedback about changes put into place based on event reports & 31 & $3.02(1.05)$ \\
\hline C3. We are informed about errors that happen in this unit & 50 & $3.38(1.20)$ \\
\hline C5. In this unit, we discuss ways to prevent errors from happening again & 57 & $3.55(1.15)$ \\
\hline Frequency of events reported (Cronbach's $a=0.75)$ & 36 & $3.00(0.99)$ \\
\hline D1. When a mistake is made, but is caught and corrected before affecting the patient, how often is this reported? & 39 & $3.14(1.21)$ \\
\hline D2. When a mistake is made, but has no potential to harm the patient, how often is this reported? & 30 & $2.84(1.14)$ \\
\hline D3. When a mistake is made that could harm the patient, but does not, how often is this reported? & 38 & $3.02(1.29)$ \\
\hline Overall perceptions of patient safety (Cronbach's $a=0.22$ ) & 44 & $3.02(0.55)$ \\
\hline A9. It is just by chance that more serious mistakes do not happen around here (R) & 35 & $2.84(1.15)$ \\
\hline A14. Patient safety is never sacrificed to get more work done & 41 & $2.94(1.18)$ \\
\hline A16. We have patient safety problems in this unit (R) & 36 & $2.83(1.22)$ \\
\hline A17. Our procedures and systems are good at preventing errors from happening & 64 & $3.50(1.10)$ \\
\hline Communication openness (Cronbach's $a=0.37$ ) & 42 & $3.12(0.85)$ \\
\hline C2. Staff will freely speak up if they see something that may negatively affect patient care & 43 & $3.17(1.21)$ \\
\hline C4. Staff feel free to question the decisions or actions of those with more authority & 35 & $2.92(1.27)$ \\
\hline C6. Staff are afraid to ask questions when something does not seem right (R) & 47 & $3.27(1.34)$ \\
\hline Teamwork across units (Cronbach's $a=0.51$ ) & 57 & $3.36(0.71)$ \\
\hline F2. Hospital units do not coordinate well with each other (R) & 54 & $3.25(1.21)$ \\
\hline F4. There is good cooperation among hospital units that need to work together & 58 & $3.39(1.21)$ \\
\hline F6. It is often unpleasant to work with staff from other hospital units (R) & 51 & $3.30(1.07)$ \\
\hline F10. Hospital units work well together to provide the best care for patients & 66 & $3.53(1.08)$ \\
\hline Staffing (Cronbach's $a=0.16$ ) & 26 & $2.49(0.73)$ \\
\hline A2. We have enough staff to handle the workload & 32 & $2.49(1.30)$ \\
\hline A5. Staff in this unit work longer hours than is best for patient care (R) & 22 & $2.39(1.15)$ \\
\hline
\end{tabular}


Table 2 Percent average positive response for an item-level and composite (Continued)

\begin{tabular}{lll}
\hline A13. We work in 'crisis mode' trying to do too much, too quickly (R) & 24 & $2.60(1.10)$ \\
Handoffs and transitions (Cronbach's $a=0.60)$ & 33 & $2.84(0.76)$ \\
F3. Things 'fall between the cracks' when transferring patients from one unit to another (R) & 30 & $2.82(1.05)$ \\
F5. Important patient care information is often lost during shift changes (R) & 37 & $2.89(1.18)$ \\
F7. Problems often occur in the exchange of information across hospital units (R) & 35 & $2.92(1.06)$ \\
F11. Shift changes are problematic for patients in this hospital (R) & 32 & $2.73(1.21)$ \\
Non-punitive response to error (Cronbach's $a=0.44)$ & 33 \\
A7. Staff feel like their mistakes are held against them (R) & 26 \\
A11. When an event is reported, it feels like the person is being written up, not the problem (R) & $37.77)$ \\
A15. Staff worry that mistakes they make are kept in their personnel file (R) & $3.76(1.04)$ \\
Overall (Cronbach's $a=0.77)$ & $36 \quad 3.05(1.06)$ \\
\hline
\end{tabular}

${ }^{a}$ Mean percentage of positive responses calculated according to AHRQ instructions for every respondent

${ }^{\mathrm{b}}$ Negatively worded items that were reverse coded (R)

also the highest rated in other studies but were areas of strength in hospitals across many countries, including Chinese [18], Lebanese [20], Taiwanese [26], and Saudi hospitals [24]. On the other hand, the dimension that had the lowest score was 'Staffing', reflecting that health care providers feel that staff allocation was not enough to handle the patient safety-related workload. A study conducted in the region [28] elaborated inadequate staffing levels as one of the reasons why patient safety is hard to achieve in countries, such as Ethiopia. Similar results were also observed in studies conducted in China [18], Lebanon [20], and Taiwan [26] but received a higher rating in the USA [19] and the Netherlands [26]. These disparities might be aroused as a result of the higher number of health care force in the developed countries. For instance, the Ethiopian health workforce is only 0.7 per 1000 population, lower than the WHO recommendation of 2.3 health workers per 1000 population [29]. However, it should be noted that staffing is part of the solution to patient safety issues but not the sole driver of change, as we can see the results from developed nations $[19,26]$ have not (yet) achieved the arbitrarily set value of $75 \%$ average positive score for all the dimensions.

It is also interesting to observe that the dimensions 'Handoffs and transitions' and 'Non-punitive response to error'-regardless of hospital type, profession, and work experience-were identified as major safety problems in this study. Health care staffs from the Middle-East, such as Palestine, Lebanon, and Saudi Arabia, were more negative about a non-punitive response to errors, whereas the American and Dutch health care staffs were more worried about information exchange when patients were handed over to the next provider and/or transferred to another unit. Although problems with handoffs and care transitions in the developed world might be due to the complexity of health care, ours was largely correlated and

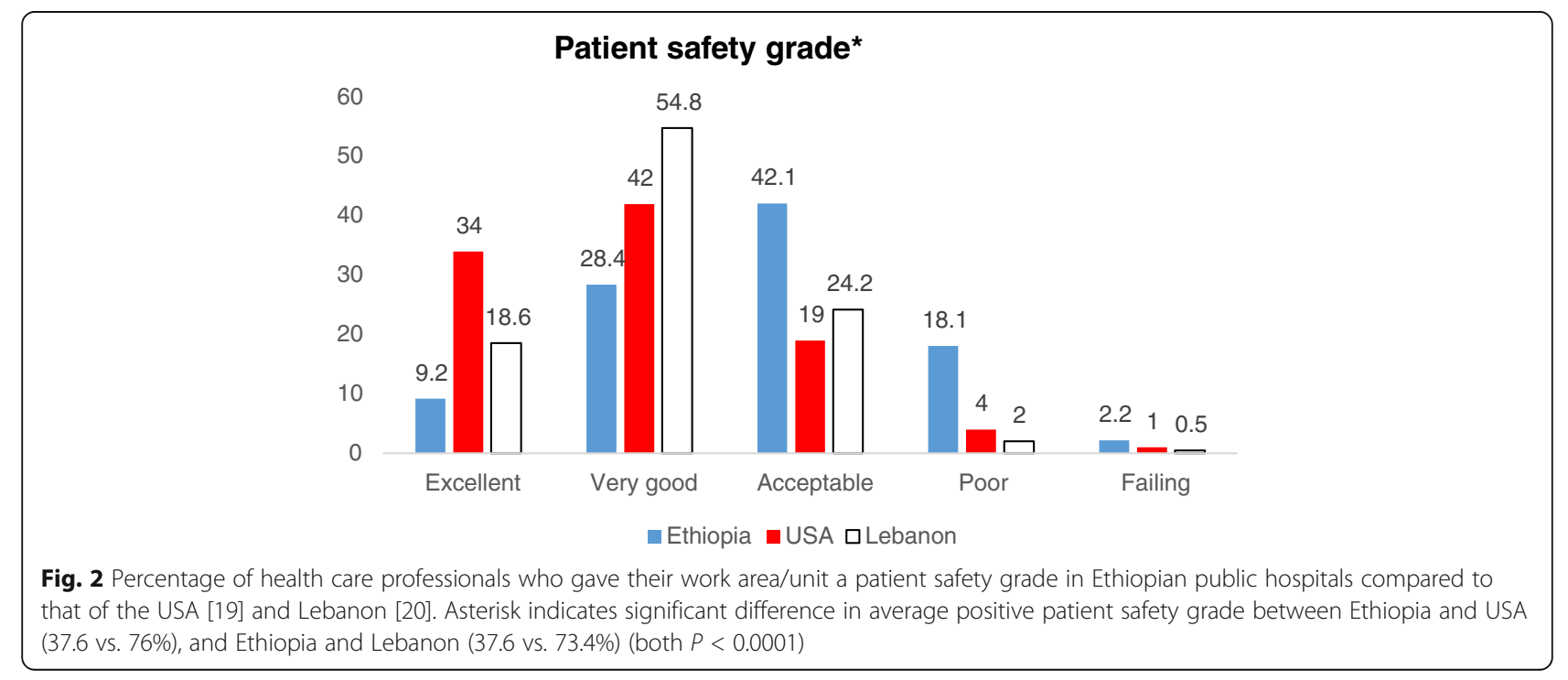




\section{Number of events reported in the past 12 months*}

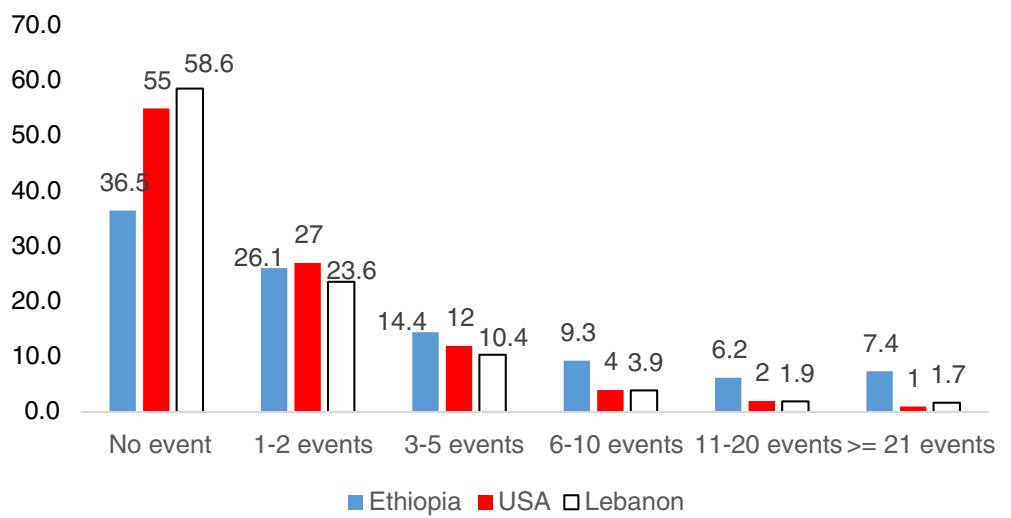

Fig. 3 Percentage of health care professionals reporting events in the past 12 months in Ethiopian public hospitals compared to that of the USA [19] and Lebanon [20]. Asterisk indicates significant difference in reporting at least one event in the past 12 months between Ethiopia and USA (63.5 vs. $45 \%$ ), and Ethiopia and Lebanon (63.5 vs. 41.4\%) (both $P<0.0001$ )

severely affected by the lack of teamwork across units, punitive response to error, and managerial inaction for promoting patient safety. The Institute of Medicine [8] has identified the challenges health care organizations move towards a safer health system; that is, moving from a culture of blame to one in which errors are treated not as personal failures but as opportunities to improve the system and prevent harm. This cultural transformation in the context of Ethiopia is not due to the willingness of staffs only but needs a strong leadership that enables staffs safety conscious, committed to learn from their mistakes and prevents errors from happening again.

Although the punitive approach to error reporting was commonly reflected in the Ethiopian health care staffs-as was the Arab world-this study uniquely identified better results in event reporting. That is two thirds of health care staffs reported at least one event in the past 1 year, when compared with the study reported in Lebanon (41\%), Palestine (47\%), Saudi Arabia (57\%), and even in the USA (45\%). However, the overall patient safety grade remained lower compared with that in the Lebanon (73.4\%), Palestine (63.5\%), Saudi Arabia (60\%), and the USA (76\%). Although previous studies [30,31] have shown that there is an association between culture and safe care practices (e.g. event reporting), this study did not show such relationship. This might be because Ethiopian staffs-particularly, other health workers not classified as nurses, physicians or pharmacists-were very enthusiastic towards event reporting, but the level of cohesiveness across the teams and professional boundaries might impact

Table 3 Distribution of two outcome variables across staff position, type of hospital, and work experience

\begin{tabular}{|c|c|c|c|c|c|c|}
\hline \multirow[t]{2}{*}{ Characteristics } & \multicolumn{3}{|c|}{ *Patient safety grade, $N(\%)$} & \multicolumn{3}{|c|}{ *Number of events reported, N (\%) } \\
\hline & Excellent/very good & Poor/failing/acceptable & $P$ value & No events & At least one event & $P$ value \\
\hline \multicolumn{7}{|l|}{ Staff position } \\
\hline Nurses & $69(47.6 \%$ & $76(52.4 \%)$ & 0.001 & $47(32 \%)$ & $100(68 \%)$ & 0.006 \\
\hline Physicians & $18(24.3 \%)$ & $56(75.7 \%)$ & & $38(53.5 \%)$ & $33(46.5 \%)$ & \\
\hline Pharmacists & $14(24.1 \%)$ & $44(75.9 \%)$ & & $22(37.9 \%)$ & $36(62.1 \%)$ & \\
\hline Others & $34(41.5 \%)$ & $48(58.5 \%)$ & & $22(28.6 \%)$ & $55(71.4 \%)$ & \\
\hline \multicolumn{7}{|l|}{ Type of hospital } \\
\hline District & $65(38.9 \%)$ & $102(61.1 \%)$ & 0.63 & $57(34.5 \%)$ & $108(65.5 \%)$ & 0.47 \\
\hline Teaching/referral & $70(36.5 \%)$ & $122(63.5 \%)$ & & $72(38.3 \%)$ & $116(61.7 \%)$ & \\
\hline \multicolumn{7}{|l|}{ Work experience } \\
\hline$<1$ year & $58(40 \%)$ & $87(60 \%)$ & 0.68 & $59(40.7 \%)$ & $86(59.3 \%)$ & 0.25 \\
\hline $1-5$ year & $60(35.3 \%)$ & $110(64.7 \%)$ & & $57(35.4 \%)$ & 104(64.6\%) & \\
\hline$>5$ year & $17(38.6 \%)$ & $27(61.4 \%)$ & & 13(27.7\%) & 34(72.3\%) & \\
\hline
\end{tabular}


Table 4 Correlations with the total score and inter-correlation of the 12 dimensions

\begin{tabular}{|c|c|c|c|c|c|c|c|c|c|c|c|c|c|}
\hline Dimensions & 1 & 2 & 3 & 4 & 5 & 6 & 7 & 8 & 9 & 10 & 11 & 12 & Total \\
\hline 1. Teamwork within units & 1 & & & & & & & & & & & & $0.57^{* *}$ \\
\hline $\begin{array}{l}\text { 2. Supervisor/manager expectations and } \\
\text { actions promoting patient safety }\end{array}$ & $0.13^{*}$ & 1 & & & & & & & & & & & $0.38^{* *}$ \\
\hline $\begin{array}{l}\text { 3. Organizational learning-continuous } \\
\text { improvement }\end{array}$ & $0.58^{* *}$ & $0.11^{*}$ & 1 & & & & & & & & & & $0.52^{* *}$ \\
\hline $\begin{array}{l}\text { 4. Management support for patient } \\
\text { safety }\end{array}$ & $0.29 * *$ & $0.15^{* *}$ & $0.31^{* *}$ & 1 & & & & & & & & & $0.59^{* *}$ \\
\hline $\begin{array}{l}\text { 5. Feedback and communication about } \\
\text { error }\end{array}$ & $0.43^{* *}$ & $0.13^{*}$ & $0.44^{* *}$ & $0.31^{* *}$ & 1 & & & & & & & & $0.68^{* *}$ \\
\hline 6. Frequency of events reported & $0.26^{* *}$ & $0.10^{*}$ & $0.28^{* *}$ & $0.30^{* *}$ & $0.53^{* *}$ & 1 & & & & & & & $0.57^{* *}$ \\
\hline 7. Overall perceptions of patient safety & 0.08 & 0.05 & 0.05 & 0.08 & $0.12^{*}$ & 0.05 & 1 & & & & & & $0.32^{* *}$ \\
\hline 8. Communication openness & $0.31^{* *}$ & $0.12^{*}$ & $0.25^{* *}$ & $0.33^{* *}$ & $0.52^{* *}$ & $0.34^{* *}$ & $0.13^{*}$ & 1 & & & & & $0.63^{* *}$ \\
\hline 9. Teamwork across units & $0.35^{* *}$ & $0.18^{* *}$ & $0.34^{* *}$ & $0.48^{* *}$ & $0.34^{* *}$ & $0.24^{* *}$ & $0.13^{* *}$ & $0.32^{* *}$ & 1 & & & & $0.66^{* *}$ \\
\hline 10. Staffing & $-0.15^{* *}$ & 0.08 & $-0.30^{* *}$ & 0.005 & $-0.10^{* *}$ & -0.07 & 0.07 & 0.03 & -0.03 & 1 & & & 0.09 \\
\hline 11. Handoffs and transitions & -0.04 & $0.17^{* *}$ & -0.01 & 0.08 & 0.06 & $0.10^{*}$ & 0.09 & $0.16^{* *}$ & $0.24^{* *}$ & 0.06 & 1 & & $0.40^{* *}$ \\
\hline 12. Non-punitive response to error & $-0.22^{* *}$ & $0.11^{*}$ & $-0.25^{* *}$ & $-0.10^{*}$ & $-0.11^{*}$ & $-0.15^{* *}$ & 0.08 & $-0.11^{*}$ & -0.03 & $0.15^{* *}$ & $0.20^{* *}$ & 1 & 0.06 \\
\hline
\end{tabular}

${ }^{*}$ Correlation is significant at $P$ value less than 0.05

${ }^{*}$ Correlation is significant at $P$ value less than 0.01

information exchange which could possibly jeopardize patient safety. Aveling et al. [28] were also described this challenge in two Eastern-African countries.

The present study has identified variations in the perception of patient safety culture across hospital types and staff positions. The results showed that nurses were found to have a positive effect on many patient safety culture predictors. As Nie et al. [18] allude to, nurses spend more time with patients and have the opportunity to deal with patient safety issues. Therefore, a higher score for nurses in safety culture is expected, and a similar finding was also reported by El-Jardali et al. [32]. The scores of district hospitals were also higher than those of teaching/referral hospitals in few of the dimensions.

This study has many limitations that need to be acknowledged. First, the assessment was given in English. Although English is the medium of instruction in the Ethiopian medical and health colleges and is the main language of communication in hospitals, staffs might not felt comfortable in responding-this might also impact the understandability of the instrument. One might think the questionnaire being in English, might affect the responses in some of the items in this study, but a recent study from Ethiopia assessing the patient safety culture assessed through native language has yet reported the same overall average positive patient safety culture score [23]. Secondly, although the internal consistency of the survey was fairly enough, the reliability analysis of individual constructs identified many factors with lower than adequate levels of reliability (alpha $<0.7$ ). This could be partly caused by the factor structure of the HSOPSC model for these items might not fit the data well [26] but also indicate the instability of aspects measured by the instrument, which is linked to professionals' perception of safety at a given time and this, in turn, is extremely subject to change [33]. Designing an optimal model becomes more apparent. Unlike other studies focused on tool development, this study was not designed for optimization of HSOPSC measurement model; however, we conducted a model modification effort to examine if a reduced model can yield more similar factor structure to that of the original HSOPSC. But this model did not show an apparently better factor structure similar to that of the HSPOS. It is, thus, the performance of an Amharic language safety culture measuring tool should be evaluated in future studies. Finally, the HSPOC as a patient safety measure might not explicitly evaluate safety issues that would arise as a result of resource limitations, such as infrastructure. There is evidence that poor infrastructure, an absence of adequate equipment and supplies, profoundly affects health care staffs to provide safe patient care [28]. This needs caution in the interpretation of findings-as the lower score values in the patient safety culture might not reflective of cultural scores per se.

\section{Conclusion}

There is a severe deficit of patient safety culture in Ethiopian public hospitals. The overall patient safety score and most of the scores related to dimensions were lower than the benchmark score. Although the punitive approach to error reporting was commonly reflected, yet two thirds of staffs reported at least one event in the past 1 year. Creating a positive patient safety culture by implementing 
actions that support all dimensions of safety culture is inevitable. The internal consistency of the total survey was fairly satisfied. However, the reliability analysis of individual constructs showed many factors less than an adequate level of Cronbach's alpha. Further research is needed to confirm the applicability of the translated version of the HSOPSC in the Ethiopian hospital settings.

\section{Additional files}

Additional file 1: Comparison of mean composite scores across type of hospital, staff position, and work experience. (DOCX $15 \mathrm{~kb}$ )

Additional file 2: Factor loadings in each item. (DOCX 16 kb)

\section{Abbreviations}

AHRQ: Agency for Healthcare Research and Quality; APPS: African Partnership for Patient Safety; HREC: Human Research Ethics Committee; HSOPSC: Hospital Survey on Patient Safety Culture; KMO: Kaiser-Meyer-Olkin

\section{Acknowledgements}

Alemayehu B. Mekonnen gratefully acknowledges the funding to support his PhD training provided by The University of Sydney International Students Scholarship.

\section{Funding}

The study did not receive any external funding.

\section{Availability of data and materials}

The datasets generated and/or analysed during the current study are available from the corresponding author on reasonable request.

\section{Authors' contributions}

All authors conceptualized the study. ABM, AJM, JEB, DM, and ZA have all made significant contributions to the scientific content of this manuscript. ABM carried out data collection and analysis. ABM carried out the initial analysis and drafted the first manuscript. AJM, JEB, DM, and ZA critically reviewed and revised the manuscript. All the authors have read and approved the final manuscript.

\section{Ethics approval and consent to participate}

The study was approved by the University of Sydney Human Research Ethics Committee (HREC) —Project Number: 2015/818 — and the Institutional Review Board of the University of Gondar, Ethiopia (O/N/P/RCS/05/624/2016).

\section{Consent for publication}

Not applicable.

\section{Competing interests}

The authors declare that they have no competing interests.

\section{Publisher's Note}

Springer Nature remains neutral with regard to jurisdictional claims in published maps and institutional affiliations.

\section{Author details}

${ }^{1}$ Faculty of Pharmacy, University of Sydney, Sydney, Australia. ${ }^{2}$ School of Pharmacy, University of Gondar, Gondar, Ethiopia. ${ }^{3}$ Department of Internal Medicine, Addis Ababa University, Addis Ababa, Ethiopia. ${ }^{4}$ Department of Internal Medicine, University of Gondar, Gondar, Ethiopia.
Received: 21 July 2017 Accepted: 31 August 2017

Published online: 13 September 2017

\section{References}

1. Jha AK, Prasopa-Plaizier N, Larizgoitia I, Bates DW, Research Priority Setting Working Group of the WHO World Alliance for Patient Safety. Patient safety research: an overview of the global evidence. Qual Saf Health Care. 2010; 19(1):42-7.

2. Jha AK, Larizgoitia I, Audera-Lopez C, Prasopa-Plaizier N, Waters H, Bates DW The global burden of unsafe medical care: analytic modelling of observational studies. BMJ Qual Saf. 2013;22(10):809-15.

3. Carpenter KB, Duevel MA, Lee PW, Wu AW, Bates DW, Runciman WB, Baker GR, Larizgoitia I, Weeks WB, Methods \& Measures Working Group of the WHO World Alliance for Patient Safety. Measures of patient safety in developing and emerging countries: a review of the literature. Qual Saf Health Care. 2010;19(1):48-54.

4. Wilson RM, Michel P, Olsen S, Gibberd RW, Vincent C, El-Assady R, et al. Patient safety in developing countries: retrospective estimation of scale and nature of harm to patients in hospital. BMJ. 2012;344:e832.

5. World Health Organization. Partnership for Safer Health Service Delivery: Evaluation of WHO African Partnerships for Patient Safety 2009-2014. Available from: http://www.who.int/patientsafety/implementation/apps/ evaluation-report.pdf. Accessed 21 Nov 2016.

6. Eshetie TC, Hailemeskel B, Mekonnen N, Paulos G, Mekonnen AB, Girma T. Adverse drug events in hospitalized children at Ethiopian University Hospital: a prospective observational study. BMC Pediatr. 2015:15:83.

7. Hightower J, Fahmi M, Gashaw M, Derso A. African partnerships for patient safety: a catalyst for change in Ethiopia. BMC Proc. 2011;5(Suppl. 6):322.

8. Kohn LTCJ, Donaldson MS, editors. To err is human: building a safer health system. Washington, DC: National Academy Press; 2000.

9. Sorra JS, Nieva VF. Hospital survey on patient safety culture, AHRQ publication no. 04-0041. Rockville: Agency for Health care Research and Quality; 2004

10. Smits M, Wagner C, Spreeuwenberg P, Wal G, Groenewegen PP. Measuring patient safety culture: an assessment of the clustering of responses at unit level and hospital level. Qual Saf Health Care. 2009;18(4):292-6.

11. Deilkas E, Hofoss D. Psychometric properties of the Norwegian version of the Safety Attitudes Questionnaire (SAQ), generic version (short form 2006). BMC Health Serv Res. 2008:8:191.

12. Smits M, Christiaans-Dingelhoff I, Wagner C, Wal G, Groenewegen PP. The psychometric properties of the "hospital survey of patient safety culture" in Dutch hospitals. BMC Health Serv Res. 2008;8:230.

13. Wagner C, Smits M, Sorra J, Huang CC. Assessing patient safety culture in hospitals across countries. Int J Qual Health Care. 2013;25(3):213-21.

14. Mekonnen AB, McLachlan AJ, Brien JE, Mekonnen D, Abay Z. Medication reconciliation as a medication safety initiative in Ethiopia: a study protocol. BMJ Open. 2016;6(11):e012322.

15. Amhara Health Bureau, Minsitry of Health, Federal Democratic Republic of Ethiopia. Available from: http://www.moh.gov.et/bg/web/guest/ amhara-regional-health-bureau. Accessed 6 Sep 2017.

16. Hospital survey on patient safety culture. Agency for Health care Research and Quality. Available from : http://www.ahrq.gov/professionals/quality-patientsafety/patientsafetyculture/hospital/index.html. Accessed 16 Nov 2015.

17. Sorra JS, Dyer N. Multi-level psychometric properties of the AHRQ Hospital survey on patient safety culture. BMC Health Serv Res. 2010;10:199.

18. Nie YL, Mao XY, Cui H, et al. Hospital survey on patient safety culture in China. BMC Health Serv Res. 2013;13:228.

19. Famolaro T, Yount N, Burns W, Flashner E, Liu H. Hospital survey on patient safety culture 2016 user comparative database report. (Prepared by Westat, Rockville, MD, under contract no. HHSA 290201300003C). Rockville: Agency for Health care Research and Quality; 2016. AHRQ Publication No. 16-0021-EF

20. El-Jardali F, Jaafar M, Dimassi H, Jamal D, Hamdan R. The current state of patient safety culture in Lebanese hospitals: a study at baseline. Int J Qual Health Care. 2010;22(5):386-95.

21. Nieva VF, Sorra J. Safety culture assessment: a tool for improving patient safety in health care organizations. Qual Saf Health Care. 2003;12(Suppl. 2): 17-23.

22. Meddings J, Reichert H, Greene MT, Safdar N, Krein SL, Olmsted RN, et al. Evaluation of the association between hospital survey on patient safety culture (HSOPS) measures and catheter-associated infections: results of two national collaboratives. BMJ Qual Saf. 2017;26(3):226-35. 
23. Wami SD, Demssie AF, Wassie MM, Ahmed AN. Patient safety culture and associated factors: a quantitative and qualitative study of health care workers' view in Jimma zone hospitals, Southwest Ethiopia. BMC Health Serv Res. 2016;16:495.

24. Alahmadi HA. Assessment of patient safety culture in Saudi Arabian hospitals. Qual Saf Health Care. 2010;19(5):e17.

25. Hamdan M, Saleem AA. Assessment of patient safety culture in Palestinian public hospitals. Int J Qual Health Care. 2013;25(2):167-75.

26. Chen IC, Li HH. Measuring patient safety culture in Taiwan using the hospital survey on patient safety culture (HSOPSC). BMC Health Serv Res. 2010;10:152.

27. Federal Democratic Republic of Ethiopia, Ministry of Health. Ethiopian National Health care Quality Strategy; 2016-2020. Available from: https:// www.medbox.org/et-policies-others/ethiopian-national-health-care-qualitystrategy-2016-2020/preview?. Accessed 6 Sep 2017.

28. Aveling EL, Kayonga Y, Nega A, Dixon-Woods M. Why is patient safety so hard in low-income countries? A qualitative study of health care workers' views in two African hospitals. Glob Health. 2015;11:6.

29. World Health Organization. Regional office for Africa. Ethiopia: analytical summary - Health workforce. Available from: http://www.aho.afro.who.int/ profiles_information/index.php/Ethiopia:Analytical_summary_-_Health_ workforce. Accessed 16 Nov 2016

30. Mardon RE, Khanna K, Sorra J, Dyer N, Famolaro T. Exploring relationships between hospital patient safety culture and adverse events. J Patient Saf. 2010;6(4):226-32.

31. Najjar S, Nafouri N, Vanhaecht K, Euwema M. The relationship between patient safety culture and adverse events: a study in Palestinian hospitals. Saf Health. 2015;1:16.

32. El-Jardali F, Dimassi $H$, Jamal D, Jaafar M, Hemadeh N. Predictors and outcomes of patient safety culture in hospitals. BMC Health Serv Res. 2011;11:45.

33. Occelli P, Quenon JL, Kret M, Domeca S, Delaperche F, Claverie O, et al. Validation of the French version of the hospital survey on patient safety culture questionnaire. Int J Qual Health Care. 2013;25(4):459-68.

\section{Submit your next manuscript to BioMed Central and we will help you at every step:}

- We accept pre-submission inquiries

- Our selector tool helps you to find the most relevant journal

- We provide round the clock customer support

- Convenient online submission

- Thorough peer review

- Inclusion in PubMed and all major indexing services

- Maximum visibility for your research

Submit your manuscript at www.biomedcentral.com/submit 